\title{
FR4-PCB Smartphone Phased Array with Improved Performance for 5G Beam-Steering Applications
}

\author{
Naser Ojaroudi Parchin ${ }^{* 1}$, Haleh Jahanbakhsh Basherlou ${ }^{2}$, Yousef Dama ${ }^{3}$, Ahmed M. \\ Abdulkhaleq $^{1}$, Yasir I. A. Al-Yasir ${ }^{1}$, and Raed A. Abd-Alhameed ${ }^{1,4}$ \\ \{N.OjaroudiParchin@Bradford.ac.uk*\} \\ ${ }^{1}$ Faculty of Engineering and Informatics, University of Bradford, Bradford BD7 1DP, UK \\ ${ }^{2}$ Bradford College, Bradford, West Yorkshire, BD7 1AY, UK \\ ${ }^{3}$ Faculty of Engineering, An-Najah National University, Palestine \\ ${ }^{4}$ Information and Communication Eng. Department, Basrah University College of Science and \\ Technology, Basrah 24001, Iraq
}

\begin{abstract}
In this paper, a high efficiency phased array antenna is introduced for fifthgeneration $(5 \mathrm{G})$ smartphones. The configuration of the design is achieved by employing eight insensitive L-ring/slot-loop resonatorss with linear array form on the top of the handset mainboard. The design exhibits high radiation performances even though the beam-steerable array is implemented on a lossy FR-4 material. The proposed design exhibit a frequency bandwidth of $18-20 \mathrm{GHz}$ with a single resonance at $19 \mathrm{GHz}$. The designed antenna exhibits wide beam-steering, high efficiencies, and sufficient gain levels at $19 \mathrm{GHz}$ of $5 \mathrm{G}$ communications. In addition, the proposed phased array design has sufficient radiation behavior in the adjacency of user-hand phantom. Moreover, its characteristics are insensitive for various substrate types.
\end{abstract}

Keywords: 5G system, cellular networks, future smartphones, substrate-insensitive antenna.

\section{Introduction}

The development of 5G technology has been an on-going process recently. It requires high data capacity and transmission speed. To support the increasing demand of high transmission rate with throughput for various fixed and mobile services, phased arrays with multiple antenna elements have been attracting much more attention for next-generation communication networks at mm-Wave frequency spectrum [1-4]. $28 \mathrm{GHz}$ is the most promising band for $5 \mathrm{G}$ wireless communications [5-8]. Increasing the operation frequency of the future wireless systems need novel and different techniques of the antenna design for future wireless devices [9-12]. Compact antennas can be arranged in linear or planar array form to be used in phased array structures with high-gain characteristics for 5G wireless communications [13-15].

A critical challenge in antenna designing for MM-wave e5G is to implement phased arrays with high radiation properties. Different from the conventional antennas (patch, monopole, PIFA and slot antennas) with omni-directional radiation, the end-fire resonators, such as Vivaldi and Yagi are more suitable for the communication between user and base station [16-20]. 
However, for smartphone applications, all these antennas could occupy huge space in the smartphone broad. Since one of the challenges of the antenna design for $5 \mathrm{G}$ smartphones is to implement antenna arrays with improved characteristics; we introduce here a new beamsteerable array with high radiation properties for future smartphone applications. Since the main dielectric is the vacuum with no losses, the resonator is able to provide high performances in terms of efficiency and antenna gain levels. furthermore, the antenna is insensitive for various dielectric constant and loss tangent values, which give a high flexibility to be used in different board. Characteristics of the single resonator and the phased array design are investigated.

\section{Results and Discussions}

The introduced phased array is arranged on a cheap FR-4 dielectric with characteristics of $\mathrm{h}_{\text {sub }}=0.8 \mathrm{~mm}$, permittivity $\left(\varepsilon_{\mathrm{r}}\right)=4.3$, and loss tangent $(\delta)=0.025$. As illustrated in Fig. 1, eight substrate-insensitive antenna elements have been with linear array arrangment and with the size of $\mathrm{W}_{\mathrm{a}} \times \mathrm{L}_{\mathrm{a}}$ is placed in the top-edge of the board with the size of $\mathrm{W}_{\text {sub }} \times \mathrm{L}_{\text {sub }}=55 \times 110 \mathrm{~mm}^{2}$. The arraned array has a low-profile of $8.5 \times 43 \mathrm{~mm}^{2}$. The EM simulation CST software was used for the investigation. The dimensions of the design parameters are listed in Table. 1.

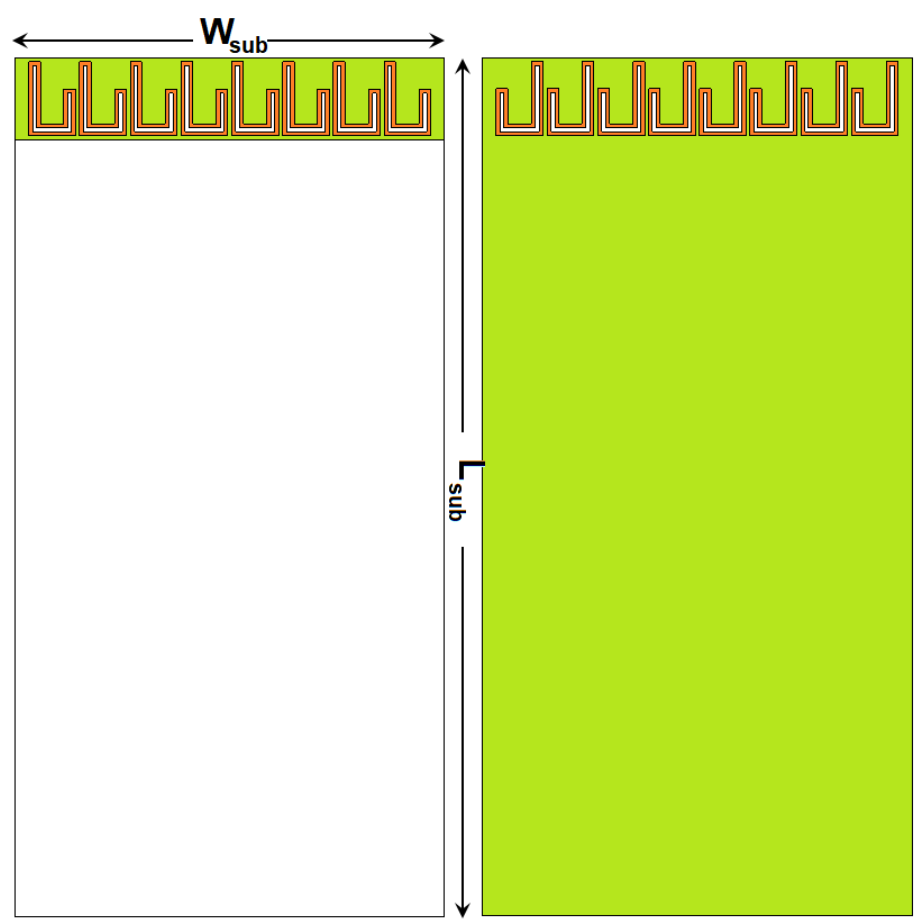

(a)

(b)

Fig. 1. (a) front and(b) back layers of the $5 \mathrm{G}$ array.

Table 1. Dimensions of the design parameters.

\begin{tabular}{llllllllll}
\hline Param. & $\mathrm{W}_{\text {sub }}$ & $\mathrm{L}_{\text {sub }}$ & $\mathrm{h}_{\text {sub }}$ & $\mathrm{W}_{\mathrm{S}}$ & $\mathrm{Ls}$ & $\mathrm{W}$ & $\mathrm{L}$ & $\mathrm{W}_{1}$ & $\mathrm{~L}_{1}$ \\
\hline
\end{tabular}




\begin{tabular}{cccccccccc}
\hline$(\mathbf{m m})$ & 55 & 110 & 0.8 & 12 & 13.5 & 1.5 & 9.5 & 0.5 & 8 \\
\hline Param. & $\mathrm{W}_{2}$ & $\mathrm{~L}_{2}$ & $\mathrm{~W}_{3}$ & $\mathrm{~L}_{3}$ & $\mathrm{~W}_{4}$ & $\mathrm{~L}_{4}$ & $\mathrm{~W}_{5}$ & $\mathrm{La}_{\mathrm{a}}$ & $\mathrm{W}_{\mathrm{a}}$ \\
\hline$(\mathbf{m m})$ & 5 & 4.5 & 3 & 6 & 1.5 & 0.5 & 0.5 & 10.5 & 51.5 \\
\hline
\end{tabular}

\section{The Single Insenstivite Radiator}

Figure 2 plots the transparent structure of the single antenna. It has low profile with simple structure and flexible in nature, and low-cost for fabrication. The $S_{11}$ of the simulated L-ring slot-loop antenna with discrete-port feeding technique is depicted in Fig. 3. As shown, the designed antenna operates at the frequency spectrum of $18-20 \mathrm{GHz}$ (with $2 \mathrm{GHz}$ bandwidth).

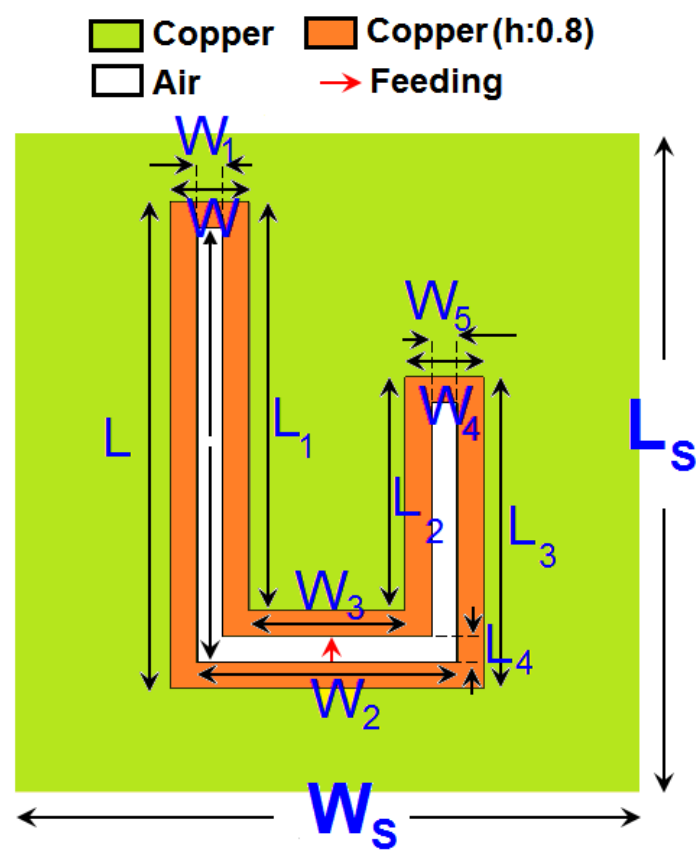

Fig. 2. The air-filled slot-loop element. 


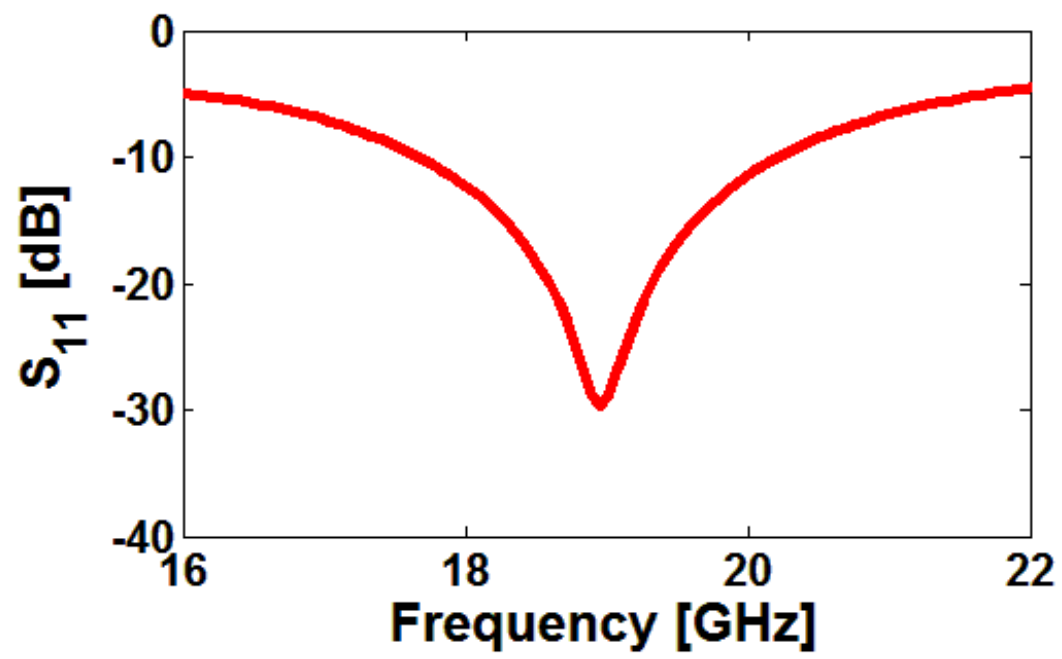

Fig. 3. $\mathrm{S}_{11}$ characteristic of the L-ring slot-loop antenna.

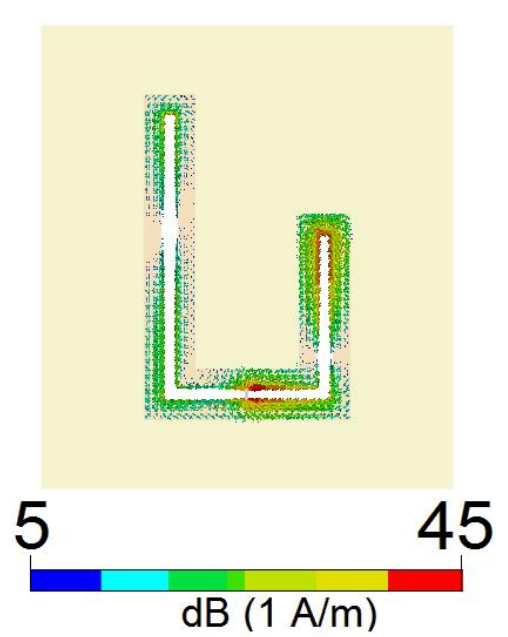

(a)

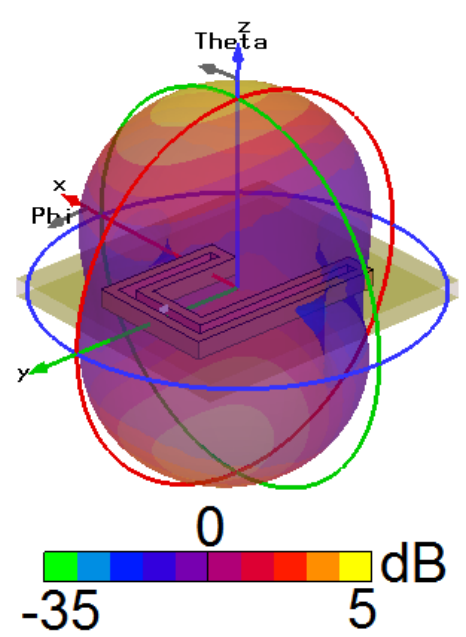

(b)

Fig. 4. (a) The surface current and (b) 3D radiation at $19 \mathrm{GHz}$.

The current density for the L-ring slot resonator at its resonant frequency ( $19 \mathrm{GHz}$ ) is plotted in Fig. 4 (a). As expected, the employed metal-ring radiator has maximum densities and behaves highly active [21-25]. The 3D radiation of the metal-ring design is represented in Fig. 4 (b). It is found that the antenna has well-defined radiation, covering the both sides of the FR-4 dielectric. In addition, it provides a high realized gain of $5 \mathrm{~dB}$. As indicated before, the design characteristics of the are insensitive to varous substrate's properties. To understand this function, the coefficient reflection $\left(S_{11}\right)$ of the antenna element for different substrate-types including FR-4, Arlon Ad-320, and Rogers-5880 are studied in Fig. 5. It is cearly shown that unlike the conventional antennas, the proposed air-filled loop array exhibits similar results and its reflection coefficient does not change for different types of substrates [26-30]. 


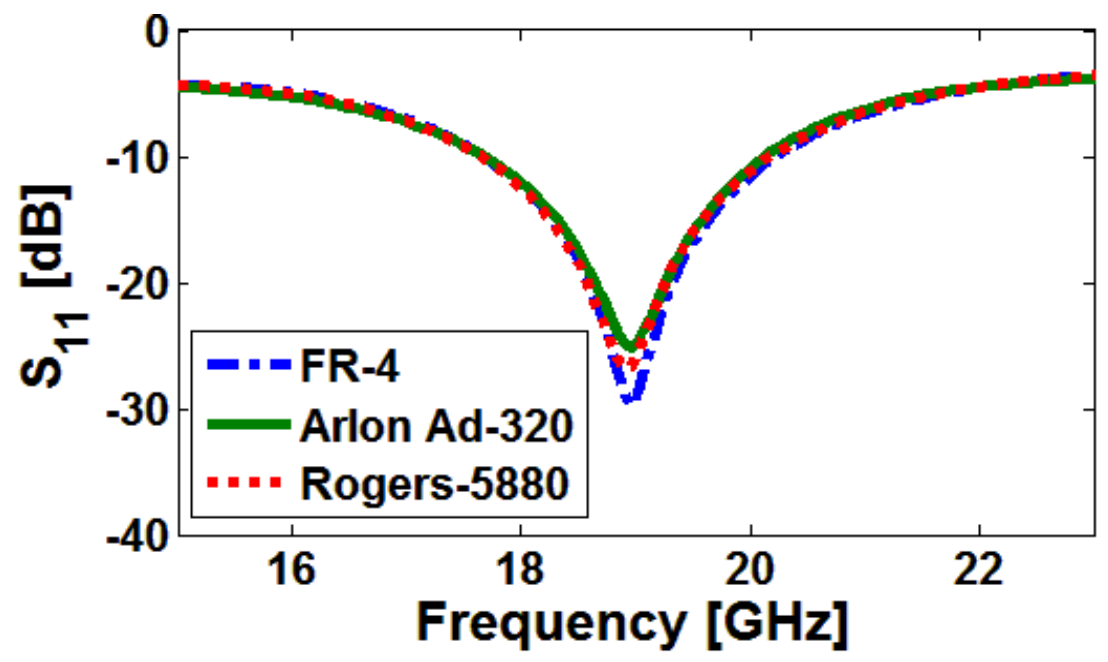

Fig. 5. The coefficient reflection $\left(S_{11}\right)$ for various substrate-types.

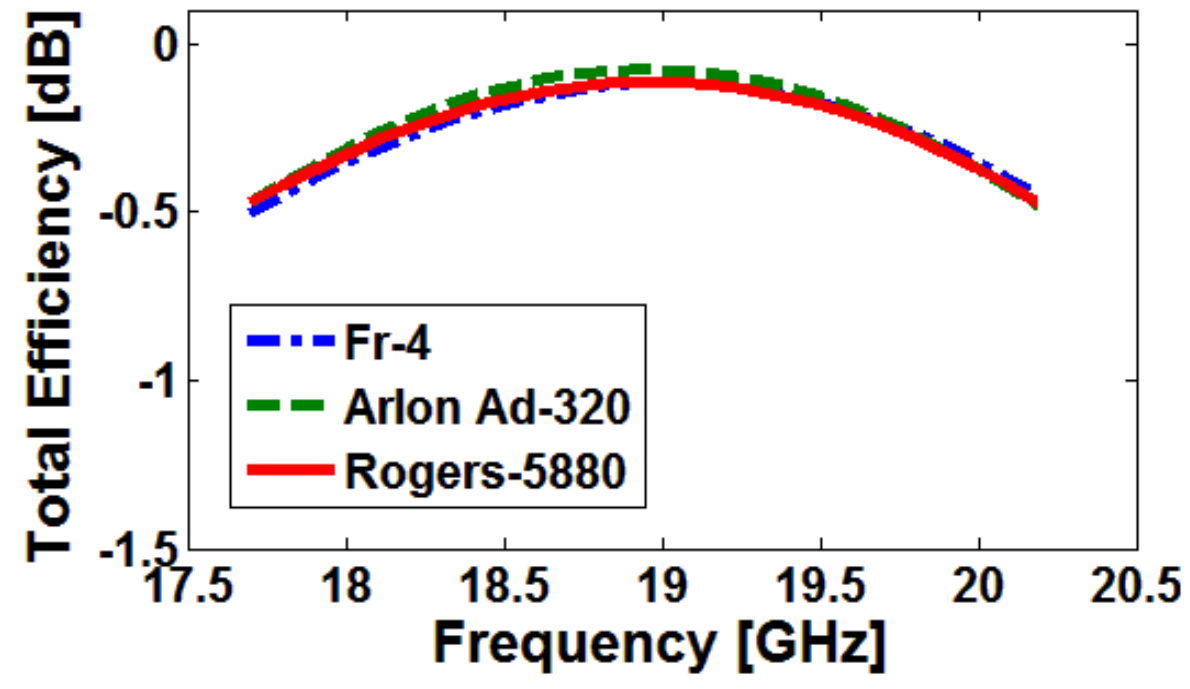

Fig. 6. The total efficiencies for various substrate-types.

The efficiencies for various substrate-types are discussed in Fig. 6. It should be noted the studied substrates have different $\delta$ (loss tangent) values which could affect the efficiency of an antenna [31-34]. However, as seen in Fig. 6, the design exhibit similar behavior with high efficiencies for various substrate-types. Figure 7 illustrates the scattering parameters $\left(S_{11} \sim S_{81}\right)$ of the phased array. As illustrated, the design exhibits quite good $S_{11} \sim S_{81}$ characteristics. Moreover, low coupling $\left(\mathrm{S}_{\mathrm{mn}}<-15 \mathrm{~dB}\right)$ is obsreved for the introduced array design. 


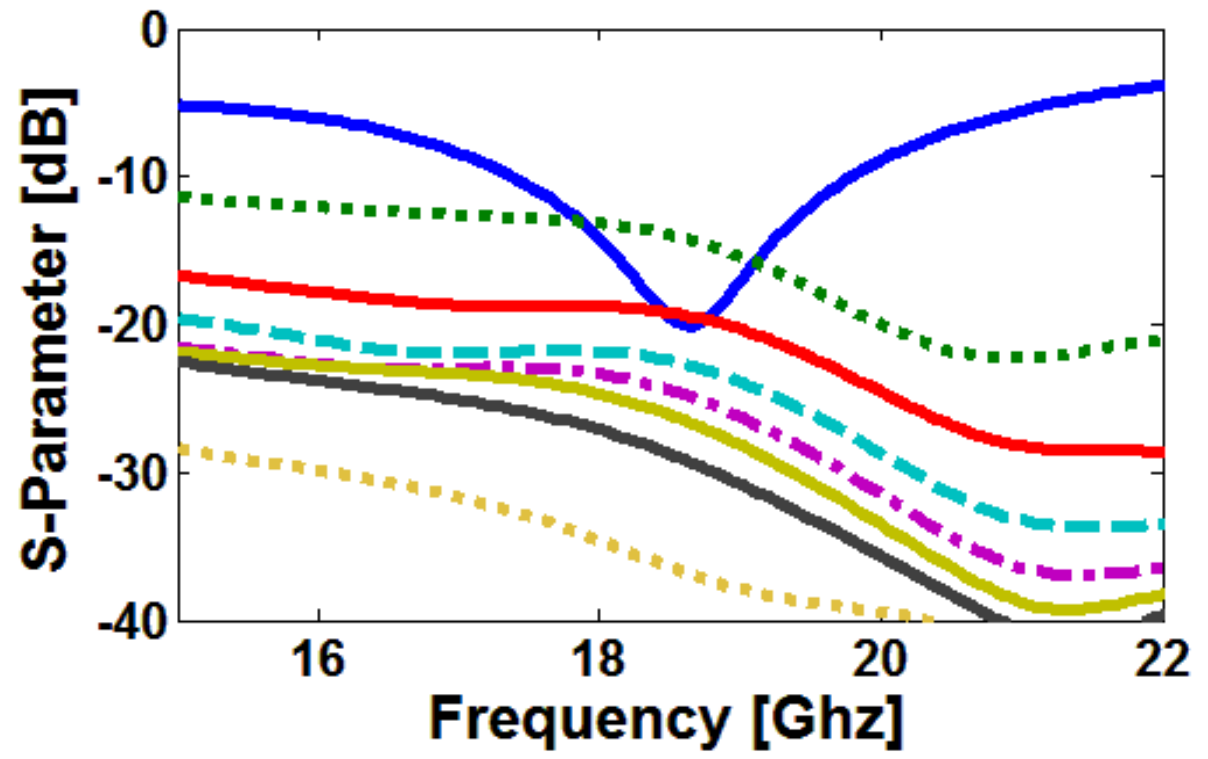

Fig. 7. S-parameters for the array.

Figure 8 illustrates the 3D beams of the designed array 5G antenna for various angles. It is seen that excellent radiation beams over of 0-70 scanning angles are provided. As shown, the design provides well-defined radiation beams at $0^{\circ}, 15^{\circ}, 30^{\circ}, 45^{\circ}, 60^{\circ}$, and $70^{\circ}$ which could cover half-space of the radiation coverage for the smartphone mainboard [35-37]. Fundamental properties of the design including directivity and efficiencies for the steered beams of the mobile-phone array at $19 \mathrm{GHz}$ design are presented in Fig. 9. Across the range of $0^{\circ}$ to $60^{\circ}$, the efficiencies are greater than $90 \%(-0.5 \mathrm{~dB})$. In addition, it provides almost constant gain levels with value around $11 \mathrm{~dB}$ at different scanning angles. 


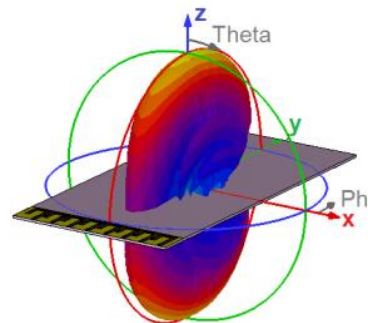

(a)

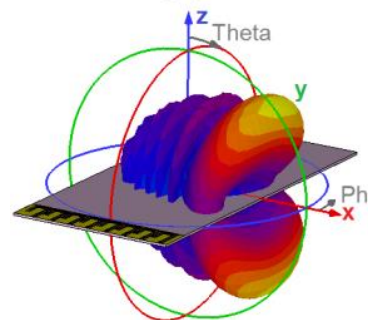

(d)

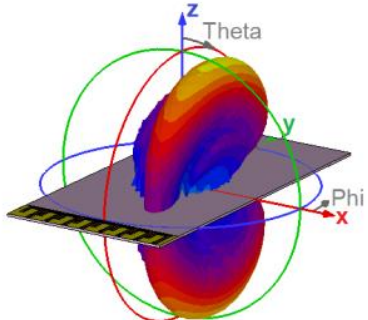

(b)

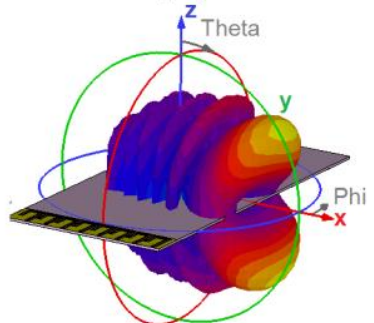

(e)

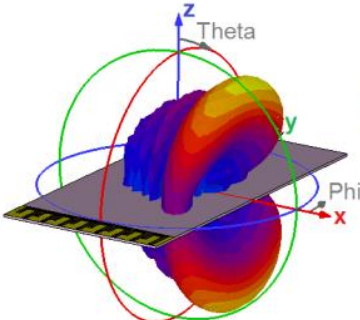

(c)

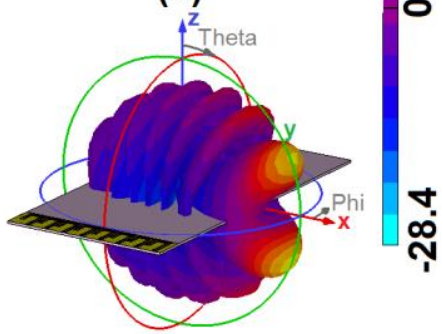

(f)

Fig. 8. 3D beams at (a) 0, (b) 15, (c) 30, (d) 45, (e) 60, and (f) 70 angles.

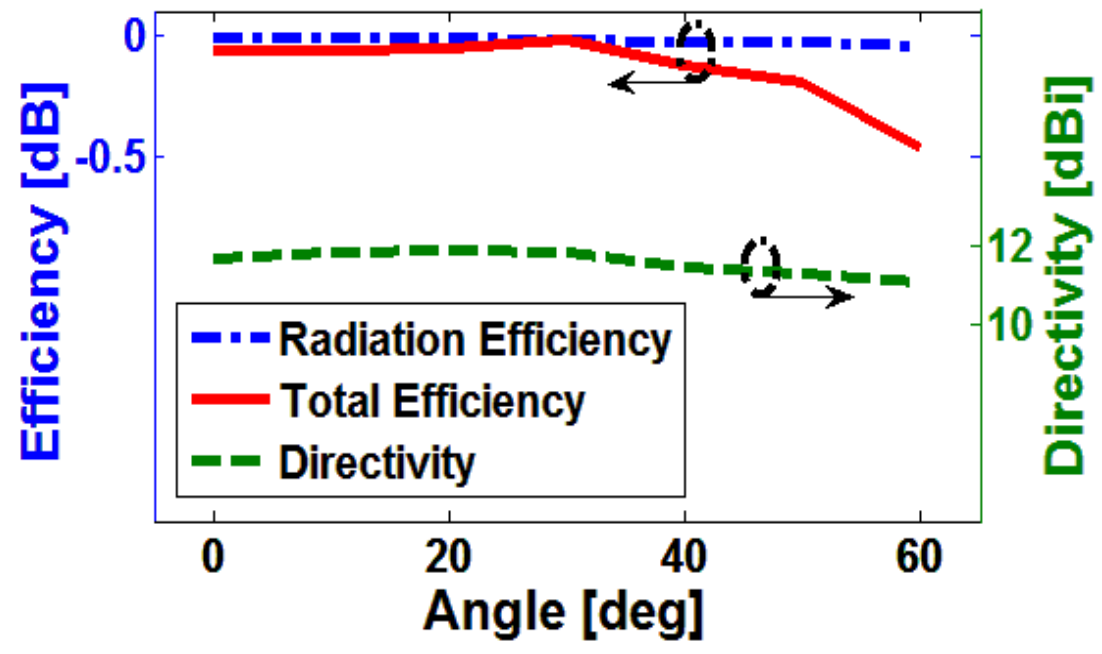

Fig. 9. Fundamental radiation characteristics at different angles ( 0 to 60 degrees).

The user-hand is a body-part that most frequently touch the handheld devices and usually has negative impacts on antenna performance [38-40]. Figure 10 represents the 3D beams at various angels $\left(0^{\circ} \sim 60^{\circ}\right)$. As plotted, the antenna provides well-defined radiation beams various angels at various angles. This might be due to compact sizes and insensitivity function of the employed element which are not highly affected by user-hand. As can be seen, the gain levels of the beams are reduced but not significantly. 


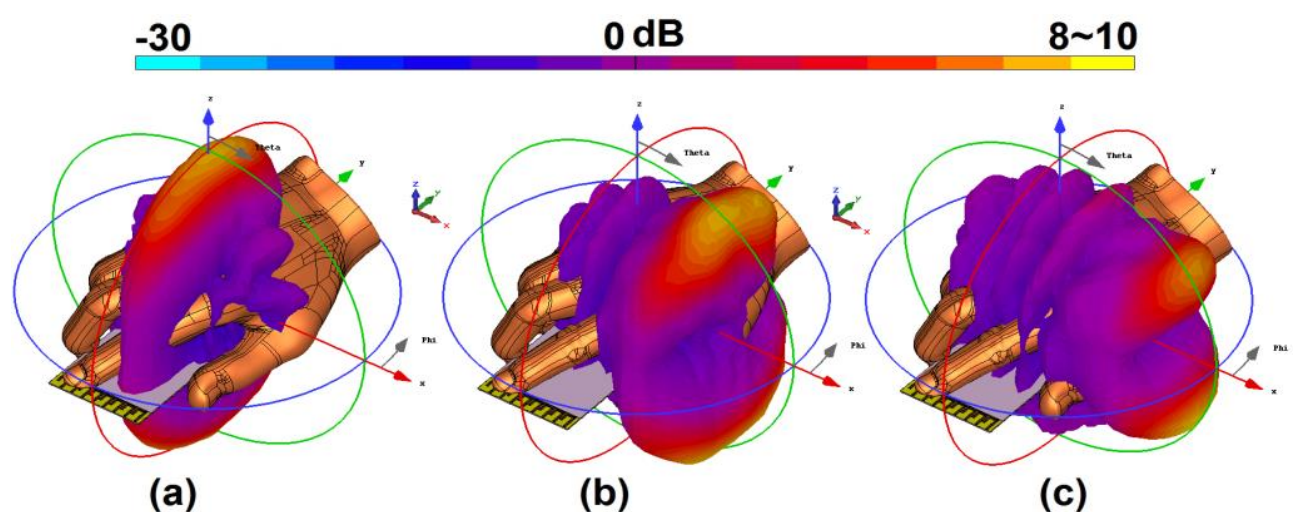

Fig. 10. 3D beams in data-mode for, (a) 0 , (b) 30, and (c) 60 degrees.

\section{Conclusion}

This manuscript proposed a insensitive design of phased array for 5G mobile communications. It is designed on the FR-4 substrate and working at 18 to $20 \mathrm{GHz}$. Eight elements of metal-ring elements are linearly arranged on the top $\mathrm{f}$ the phone PCB. Sufficient and quite good outputs have been achieved for the presented design. It also offers sufficient performance in data-mode with hand phantom.

Acknowledgments. This work is supported by the European Union's Horizon 2020 research and innovation programme under grant agreement H2020-MSCA-ITN-2016 SECRET-722424.

\section{References}

[1] Osseiran, A. et al.: Scenarios for 5G mobile and wireless communications: the vision of the METIS project. IEEE Commun. Mag. Vol. 52, pp. 26-35 (2014)

[2] Parchin, N. O. et al.: Microwave/RF Components for 5G Front-End Systems.Avid Science. pp. 1200, 2019.

[3] Roh, W. et al.: Millimeter-wave beamforming as an enabling technology for 5G cellular communications: Theoretical feasibility and prototype results. IEEE Commun. Mag. Vol. 52, pp. 106-113 (2014)

[4] Ojaroudiparchin, N. et al.: Wide-scan phased array antenna fed by coax-to-microstriplines for 5G cell phones. MIKON Conference, Krakow, Poland, May (2016)

[5] Rajagopal, S. Abu-Surra, S. Pi, Z. and Khan, F.: Antenna array design for multi-gbps mmwave mobile broadband communication. Proc. IEEE GLOBECOM'2011, Texas, USA, pp. 1-6 (2011)

[6] Parchin, N. O. Abd-Alhameed, R. A.: A compact Vivaldi antenna array for 5G channel sounding applications. EuCAP, London, UK (2018)

[7] Wang, Y. et al.: 5G mobile: Spectrum broadening to higher-frequency bands to support high data rates. IEEE Vehicular Technology Magazine. Vol. 9, pp. 39-46 (2014)

[8] Parchin, N. O. et al.: Frequency-switchable patch antenna with parasitic ring load for 5G mobile terminals. International Symposium on Antennas and Propagation (ISAP), Xian, China (2019)

[9] Ojaroudiparchin, N. et al.: Beam-steerable microstrip-fed bow-tie antenna array for fifth generation cellular communications. EuCAP 2016, Switzerland (2016)

[10] Parchin, N. O. et al.: Reconfigurable phased array 5G smartphone antenna for cognitive cellular networks. $2^{\text {th }}$ Telecommunications Forum, 25-27 November, Belgrade, Serbia (2019) 
[11] Parchin, N. O. et al.: Design of low cost FR4 wide-band antenna arrays for future 5G mobile communications. International Symposium on Antennas and Propagation (ISAP), Xian, China (2019)

[12] Tang, M.-C. Ziolkowski, R. W. and Xiao, S.: Compact hyper-band printed slot antenna with stable radiation properties. IEEE Trans. Antennas Propag. Vol. 62, pp. 2962-2969 (2014)

[13] Gupta, P.: Evolvement of mobile generations: $1 \mathrm{G}$ to 5G. International Journal for Technological Research in Engineering. vol. 1, pp. 152-157 (2013)

[14] Parchin N. O. et al.: Design of Vivaldi antenna array with end-fire beam steering function for 5G mobile terminals. TELFOR 2015. 24-26 Nov., Belgrade, Serbia, pp. 587-590 (2015)

[15] Chen, Q. Gong, Z. Yang, X. Wang, Z. and Zhang, L.: Design considerations for millimeter wave antennas within a chip package. IEEE International Workshop on Anti-counterfeiting, Security, Identification. 16-18 April, Xiamen, Fujian 13-17 (2007)

[16] Ojaroudi Y., et al.: Circularly polarized microstrip slot antenna with a pair of spur-shaped slits for WLAN applications, Microw. Opt. Technol. Lett. Vol. 57, pp. 756-759 (2015)

[17] Hong, W. Baek, K. Lee, Y. and Kim, Y. G.: Design and analysis of a low-profile $28 \mathrm{GHz}$ beam steering antenna solution for future $5 \mathrm{G}$ cellular applications. IEEE international microwave symposium. 1-6 June 2014, Tampa Bay, Florida (2014)

[18] Parchin, N. O. et al.:MM-wave phased array quasi-yagi antenna for the upcoming $5 \mathrm{G}$ cellular communications. Applied Sciences, Vol. 9, pp. 1-14 (2019)

[19] Amitay, N. Galindo, V. Wu, C. P.: Theory and analysis of phased array antennas. WileyInterscience, New York (1972)

[20] P Ojaroudi, N. and Ghadimi, N.: Design of CPW-fed slot antenna for MIMO system applications. Microw. Opt. Technol. Lett. Vol. 56, pp. 1278-1281 (2014)

[21] archin N. O. et al.: High-Performance Yagi-Uda Antenna Array for $28 \mathrm{GHz}$ Mobile Communications. TELFOR 2019, 25-27 Nov., Belgrade, Serbia (2019)

[22] Chen, Q. et al.: Design considerations for millimeter wave antennas within a chip package. International Workshop on Anti-counterfeiting, Security, Identification. April, Xiamen, pp. 13-17 (2007)

[23] Y.Al-Yasir, et al.: A new polarization-reconfigurable antenna for 5G wireless communications. BroadNets'2018, Faro, Portugal (2018)

[24] Valizade, A., et al.: Band-notch slot antenna with enhanced bandwidth by using $\Omega$-shaped strips protruded inside rectangular slots for UWB applications. Appl. Comput. Electromagn. Soc. (ACES) J., Vol. 27, (10), pp. 816-822 (2012)

[25] Ojaroudi, N.: Small microstrip-fed slot antenna with frequency band-stop function. $21^{\text {th }}$ Telecommunications Forum. TELFOR 2013, 27 - 28 November, Belgrade, Serbia, (2013)

[26] Ojaroudi, N. et al.: Quadband planar inverted-f antenna (PIFA) for wireless communication systems. Progress In Electromagnetics Research Letters. Vol. 45, pp. 51- 56 (2014)

[27] Salman J. , et al.: Effects of the loss tangent, dielectric substrate permittivity and thickness on the performance of circular microstrip antennas. Journal of Engineering and Development. pp. 1-13 (2006)

[28] Mazloum, J. et al.: Bandwidth enhancement of small slot antenna with a variable band-stop function. Wireless Personal Communications. Vol. 95, pp. 1147-1158 (2017)

[29] Al-Yasir, Y. et al.: New radiation pattern-reconfigurable $60-\mathrm{GHz}$ antenna for $5 \mathrm{G}$ communications. Modern Printed Circuit Antennas. IntechOpen (2019)

[30] Ojaroudi, N.: Circular microstrip antenna with dual band-stop performance for ultra-wideband systems. Microw. Opt. Technol. Lett. Vol. 56, pp. 2095-2098 (2014)

[31] Ojaroudi, N.: Design of microstrip antenna for 2.4/5.8 GHz RFID applications. German Microwave Conference, GeMic 2014, RWTH Aachen University, Germany, March 10-12 (2014)

[32] Parchin, N. O.: Low-profile air-filled antenna for next generation wireless systems. Wireless Personal Communications. Vol. 97, pp. 3293-3300 (2017)

[33] Parchin, N. O. et al.: A substrate-insensitive antenna array with broad bandwidth and high efficiency for 5G mobile terminals," Photonics \& Electromagnetics Research Symposium (PIERS), Xiamen, China (2019) 
[34] Parchin, N. O. et al.: Frequency reconfigurable antenna array for mm-Wave 5G mobile handsets. BroadNets, Faro, Portugal, 19-20 September (2018)

[35] Ullah, A. et al.: Coplanar waveguide antenna with defected ground structure for 5G millimeter wave communications. IEEE MENACOMM'19, Bahrain (2019)

[36] Siahkal-Mahalle, B. H. et al.: A new design of small square monopole antenna with enhanced bandwidth by using cross-shaped slot and conductor-backed plane. Microwave Opt Technol Lett, Vol. 54, pp. 2656-2659 (2012)

[37] Ojaroudiparchin, N. et al.: $8 \times 8$ planar phased array antenna with high efficiency and insensitivity properties for 5G mobile base stations. in Proc. 10th Eur. Conf. Antennas Propag. (EuCAP), Davos, Switzerland, April, pp. 1-5 (2016)

[38] Ojaroudiparchin, N., Shen, M. and Pedersen, G. F.: MM-wave dielectric resonator antenna (DRA) with wide bandwidth for the future wireless networks. International Conference on Microwaves, Radar and Wireless Communications (MIKON). Poland, May (2016)

[39] Parchin, N. O. et al.: Frequency reconfigurable antenna array with compact end-fire radiators for 4G/5G mobile handsets. IEEE 2nd 5G World Forum (5GWF), Dresden, German (2019)

[40] Ilvonen, J. et al.: Mobile terminal antenna performance with the user's hand. IEEE Antenna and Wreless Propagation Letters. Vol. 10, pp. $772-775$ (2000) 